\title{
Mathematics Education in Singapore
}

\author{
Berinderjeet Kaur, Cheow Kian Soh, Khoon Yoong Wong, \\ Eng Guan Tay, Tin Lam Toh, Ngan Hoe Lee, Swee Fong Ng, \\ Jaguthsing Dindyal, Yeen Peng Yen, Mei Yoke Loh, \\ Hwee Chiat June Tan and Lay Chin Tan
}

\begin{abstract}
Mathematics education in Singapore is a shared responsibility of the Ministry of Education (MOE) and the National Institute of Education (NIE). The MOE overseas the intended, implemented and attained curriculum in all schools while the NIE is involved in teacher preparation and development and also research in mathematics education. Therefore this report has two sections respectively, the first describes the education system and school mathematics curricula while the second briefly provides relevant information on teacher preparation and development and mathematics education research in Singapore.
\end{abstract}

Keywords Singapore - Mathematics education - Curriculum - Teacher education - Research

\section{Introduction}

Mathematics education in Singapore is a shared responsibility of the Ministry of Education (MOE) and the National Institute of Education (NIE). MOE develops the national mathematics curriculum and oversees its implementation in all schools, while the NIE is involved in teacher preparation and development and also research in mathematics education. This report comprises two sections: the first describes the education system and school mathematics curricula while the second provides relevant information on teacher preparation and development and mathematics education research in Singapore.

B. Kaur $(\bowtie) \cdot$ K.Y. Wong $\cdot$ E.G. Tay $\cdot$ T.L. Toh $\cdot$ N.H. Lee $\cdot$ S.F. Ng $\cdot$ J. Dindyal National Institute of Education, Nanyang Technological University, Singapore, Singapore e-mail: berinderjeet.kaur@nie.edu.sg

C.K. Soh $(\varangle)$ · Y.P. Yen · M.Y. Loh · H.C.J. Tan · L.C. Tan

Ministry of Education, Singapore, Singapore

e-mail: SOH_Cheow_Kian@moe.edu.sg

(C) The Author(s) 2015 


\section{The Education System and School Mathematics Curricula}

Education in Singapore has evolved through a continual process of change, improvement and refinement since the country gained independence in 1965. Today, all children receive at least 10 years of general education in over 350 primary, secondary and post-secondary schools. There are diverse pathways and opportunities for students to discover their talents, realize their potential, and develop a passion for life-long learning. Singapore's education system largely follows a 6-4-2 structure, with 6 years of primary (Grade 1-6), 4 years of secondary (Grade 7-10) and 2 years of pre-university (Grade 11-12) education (MOE 2012).

Mathematics is a compulsory subject from Primary 1 up to the end of secondary education. In the early grades, about $20 \%$ of the school curriculum time is devoted to mathematics so that students build a strong foundation to support further learning in later years. The mathematics curriculum is centrally planned by MOE. However, flexibility is given to schools to implement the curriculum to best meet the abilities and interests of students. The mathematics curriculum is reviewed every 6 years with consultation of key stakeholders and partners to ensure that it meets the needs of the nation.

The mathematics curriculum aims to enable students to acquire and apply mathematical concepts and skills; develop cognitive and metacognitive skills through a mathematical approach to problem solving; and develop positive attitudes towards mathematics. A single mathematics curriculum framework (MOE 2007) unifies the focus of the mathematics curriculum for all levels from primary to preuniversity. The focus is on developing students' mathematical problem-solving abilities through five integral components namely, concepts, skills, processes, attitudes, and metacognition.

A spiral approach is used in the design of the mathematics syllabuses from primary to pre-university. At every level, the syllabuses comprise a few content strands (e.g. number and algebra, geometry and measurement, statistics and probability), facilitating connections and inter-relationships across strands. The content in each strand is revisited and taught with increasing depth across levels. There is differentiation in the content, pace and focus among syllabuses within the same levels to cater to different student profiles.

Primary 1-4 students follow a common mathematics syllabus, covering the use of numbers in measurements, understanding of shapes and simple data analysis. At Primary 5-6, there are two syllabuses: the Standard Mathematics syllabus builds on the concepts and skills studied in Primary 1-4, whereas the Foundation Mathematics syllabus revisits some of the important concepts and skills taught earlier. At the secondary level, there are 5 different syllabuses for students in the Express, Normal (Academic) and Normal (Technical) courses. These syllabuses include concepts and skills in number and algebra, measurement and geometry, and statistics and probability. Calculus and trigonometry are covered in the additional mathematics syllabuses for Secondary 3-4 students who are more mathematically-inclined. At the pre-university level, mathematics is an optional subject. Three syllabuses 
( $\mathrm{H} 1, \mathrm{H} 2$ and $\mathrm{H} 3)$ are available to prepare students for different university courses and the use of graphing calculators is expected.

There are also programmes to support the slow progress students and stretch those talented in mathematics. Primary 1 students (about $5 \%$ ) who lack ageappropriate numeracy skills are given support through the Learning Support Programme for Mathematics where they are taught in small groups by specially-trained teachers. For gifted learners, there is an enriched mathematics curriculum that emphasizes problem solving, investigations, making conjectures, proofs and connections among concepts. The NUS High School of Mathematics and Science also offers mathematically talented students a broad-based 6-year programme that includes undergraduate level topics and a mathematics research component.

For the teaching of mathematics at the primary levels the Concrete-PictorialAbstract (C-P-A) approach, introduced in 1980, is prevalent. Since 1990s, it has been used together with activity-based learning to encourage active participation by students in the learning process. In the early 1980s, MOE also developed the model method for solving word problems at the primary level (MOE 2009). This method provides a visual tool for students to process and analyse information and develop a sequence of logical steps to solve word problems. The model method is also used with algebra to help students formulate algebraic equations to solve problems in lower secondary mathematics. This facilitates the transition from a dominantly arithmetic approach at the primary level to an algebraic one at the secondary level. At the secondary and pre-university levels, teacher-directed inquiry and direct instruction are common. These approaches are used with other activities and group work to engage students in learning mathematics.

Resources are critical to curriculum implementation and effective delivery of mathematics lessons. Textbooks are essential materials to help teachers understand the emphases and scope of the syllabuses, and for students to learn independently. In the late 1990s, MOE devolved textbook writing to commercial publishers to allow for a greater variety of textbooks. Quality is assured through a rigorous textbook authorization and approval process by MOE. Besides textbooks, MOE also produces additional materials to support teachers especially at the primary levels.

\section{Teacher Preparation and Development, and Research in Mathematics Education}

\section{The NIE and Teacher Education}

The National Institute of Education (NIE) is an autonomous institute within the Nanyang Technological University and sole teacher education institution in Singapore. It offers both pre-service and in-service education programmes ranging from diploma to doctorate levels. Its present model of Teacher Education for the 21st century $\left(\mathrm{TE}^{21}\right)$ is unique and has six foci intended to enhance the key elements of teacher education. The foci are the Values ${ }^{3}$, Skills and Knowledge $\left(\mathrm{V}^{3} \mathrm{SK}\right)$ model, 
the Graduand Teacher Competencies (GTC) framework, strengthening the theorypractice nexus, an extended pedagogical repertoire, an assessment framework for 21st century teaching and learning, and enhanced pathways for teacher professional development (NIE 2009). In particular the $\mathrm{V}^{3} \mathrm{SK}$ model explicates three dimensions of values for the teacher, viz. learner-centredness, teacher identity and service to the profession and community, without which the beginning teacher may easily lose her focus in an increasingly technological and knowledge-driven world. The GTC framework makes clear the competencies to which the student teacher should aspire to attain or be aware of in his studies at NIE. This is a distinct attempt to state what must be achieved in one's pre-service teacher education and also what should be reasonably accomplished only after some years of experience as a teacher.

\section{Pre-service Education of Mathematics Teachers}

Pre-service education provides the crucial initial training that can have long-term impacts on the quality of future teachers in an education system. Besides education courses and the practicum, trainee teachers take mathematics-related courses called Curriculum Studies (methodology), Subject Knowledge (deeper understanding of school mathematics), and Academic Studies (tertiary mathematics). These courses are taught by mathematicians, mathematics educators, and "mathematician educators" (those with expertise in both areas) from the same Mathematics and Mathematics Education Academic Group. These courses stress the rigour of mathematics contents and relevance to local school contexts and school mathematics, in particular, the model method used in problem solving. Locally developed resources (Lee and Lee 2009a, b) used in these courses combine local experience and research with international "best practices". Blended learning is used in teacher education courses in response to the significant roles of ICT in instruction as well as the changing characteristics of the trainee teachers. Findings from IEA's Teacher Education and Development Study in Mathematics (TEDS-M) (Tatto et al. 2012) show that NIE trainee teachers scored above international average in mathematics content and pedagogical content knowledge, and most of them expressed strong commitment to the teaching profession as their life-long career.

\section{Professional Development of Mathematics Teachers}

Since 1998 all teachers in Singapore are entitled to $100 \mathrm{~h}$ of training and coreupgrading courses each year to keep abreast with current knowledge and skills. The Professional Development (PD) is funded by the MOE. Teachers have different pathways to upgrade their knowledge and skills through the Professional Development Continuum Models (PCDM) of the MOE. The MOE works closely with NIE to design courses for practicing teachers. Numerous academic courses offered 
by NIE lead to postgraduate degrees. For example, in order to upgrade mathematics teachers' content knowledge, a unique master degree programme MSc (Mathematics for Educators) is offered by NIE. The mathematics chapter of the Academy of Singapore Teachers (AST), the Association of Mathematics Educators (AME) and the Singapore Mathematical Society (SMS) are also actively engaged in the PD of teachers. They hold relevant annual meetings, seminars and conferences for teachers. Teachers may also attend international conferences or study trips to widen their perspectives on mathematics education. Lastly, teachers are also engaging in professional learning and development by participating in research projects at the school level. Examples of two such projects are the Enhancing the pedagogy of mathematics teacher (EPMT) project (Kaur 2011) and the Think-Things-Through (T3) project (Yeap and Ho 2009).

\section{Mathematics Education Research in Singapore}

Research is undertaken by graduate students and university scholars. Since 2002, the MOE through the Office of Education Research (OER) at NIE has funded research to inform policy and practice so as to improve education in Singapore. Some of the projects in mathematics education that have been funded and completed are as follows: An exploratory study of low attainers in primary mathematics (Kaur and Ghani 2012); The Singapore mathematics assessment and pedagogy project (Wong et al. 2012); Individual differences in mathematical performance: social-cognitive and neuropsychological correlates (Lee and Ng 2011); Mathematical problem solving for everyone (Toh et al. 2011), Student perspective on effective mathematics pedagogy (Kaur 2009), and Teaching and learning mathematical word problems: A comparison of the model and symbolic methods (Lee et al. 2011). These projects were carried out by university scholars in collaboration with students, teachers and research staff at NIE. Research studies undertaken by graduate students almost always culminate in dissertations, thesis or academic reports, all of which are available at the NIE library repository.

Open Access This chapter is distributed under the terms of the Creative Commons Attribution Noncommercial License, which permits any noncommercial use, distribution, and reproduction in any medium, provided the original author(s) and source are credited.

\section{References}

Kaur, B. (2009). Characteristics of good mathematics teaching in Singapore grade eight classrooms-A juxtaposition of teachers' practice and students' perception. ZDM-The International Journal on Mathematics Education, 41(3), 333-347.

Kaur, B. (2011). Enhancing the pedagogy of mathematics teachers (EPMT) project: A hybrid model of professional development. ZDM - The International Journal on Mathematics Education, 43(7), 791-803. 
Kaur, B. \& Ghani, M. (Eds.). (2012). Low attainers in primary mathematics. Singapore: World Scientific.

Lee, K. \& Ng, S.F. (2011). Neuroscience and the teaching of mathematics. Educational Philosophy and Theory, 43(1), 81-86.

Lee, K., Ng, S.F., Bull, R., Pe, M.L. \& Ho, R.M.H. (2011). Are patterns important? An investigation of the relationships between proficiencies in patterns, computation, executive functioning, and algebraic word problems. Journal of Educational Psychology, 103(2), 269-281.

Lee, P. Y., \& Lee, N. H. (Eds.). (2009a). Teaching primary school mathematics: A resource book (2nd ed.). Singapore: McGraw-Hill Education (Asia).

Lee, P. Y., \& Lee, N. H. (Eds.). (2009b). Teaching secondary school mathematics: A resource book (2nd \& updated ed.). Singapore: McGraw-Hill Education (Asia).

Ministry of Education (MOE, 2007). Primary mathematics syllabus. Singapore: Author

Ministry of Education (MOE, 2012). The Singapore education landscape. Retrieved December 3, 2012, from http://www.moe.gov.sg/education/landscape/

Ministry of Education (MOE, 2009). The Singapore model method for learning mathematics. Singapore: Marshall Cavendish Education

NIE (National Institute of Education) (2009). TE21: A teacher education model for the $21^{\text {st }}$ century. Singapore: Author.

Tatto, M.T., Schwille, J., Senk, S.L., Ingvarson, L., Rowley, G., Peck, R., Bankov, K., Rodriguez, M., \& Reckase, M. (2012). Policy, practice, and readiness to teach primary and secondary mathematics in 17 countries: Findings from the IEA Teacher Education and Development Study in Mathematics (TEDS-M). Amsterdam, The Netherlands: International Association for the Evaluation of Educational Achievement (IEA).

Toh, T.L., Quek, K.S., Leong, Y.H., Dindyal, J. \& Tay, E.G. (2011). Making mathematics practical: An approach to problem solving. Singapore: World Scientific.

Wong, K.Y., Oh, K.S., Ng, Q.T.Y., \& Cheong, J.S.K. (2012). Linking IT-based semi-automatic marking of student mathematics responses and meaningful feedback to pedagogical objectives. Teaching Mathematics Applications, 31(1), 57-63.

Yeap, B.H. \& Ho, S.Y. (2009). Teacher change in an informal professional development programme: The 4-I model. In K.Y. Wong, P.Y. Lee, Kaur, B., P.Y. Foong, \& S.F. Ng (Eds.) Mathematics education: The Singapore journey (pp. 130 - 149). Singapore: World Scientific. 